\title{
The Role of CCUS in North America Energy System Decarbonization
}

\author{
Nadejda Victor \\ Leidos \\ Peter Balash \\ NETL/DOE
Christopher Nichols
NETL/DOE

One of the key energy technologies that can significantly reduce carbon dioxide $\left(\mathrm{CO}_{2}\right)$ emissions across industrial processes and power generation is carbon capture, utilization, and storage (CCUS). We explore different scenarios of North America long-term energy system development with respect to CCUS technologies and, particularly, $\mathrm{CO}_{2}$-enhanced oil recovery (EOR).

Keywords: Carbon Capture, Utilization, and Storage (CCUS), Carbon Dioxide ( $\left.\mathrm{CO}_{2}\right)$, Enhanced Oil Recovery (EOR)

\section{EXECUTIVE SUMMARY}

North America (U.S., Canada, and Mexico, jointly) is on track to achieve a significant (about 50\%) carbon dioxide $\left(\mathrm{CO}_{2}\right)$ reduction by 2050 (relative to 2015) using $\mathrm{CO}_{2}$ taxation. However, $\mathrm{CO}_{2}$ taxation policy primarily affects the power generation sector. Achievement of the 2015 United Nations Climate Change Conference (COP21) commitments by North America requires immediate deployment of available clean energy technologies, including carbon capture, utilization, and storage (CCUS), and stronger decarbonization policies. Delay in decarbonization might imply the need for more radical intervention, e.g., a massive deployment of negative emissions technologies.

\section{INTRODUCTION}

With the ratification of the Paris Agreement, 195 nations committed to holding the increase in the global average temperature below $2{ }^{\circ} \mathrm{C}$ above pre-industrial levels. North America (U.S., Canada, and Mexico) formally joined the Paris Agreement in April 2016 [UN, 2019]. The U.S. indicated it would pull out of the agreement, though the exit won't be complete until 2020 [Tollefson, 2017; Diringer, 2017]. However, a new alliance of states, cities, and corporations has already vowed to help the U.S. meet the Paris reduction goals. Canada committed to a $30 \%$ reduction of 2005 greenhouse gas (GHG) emissions by 2030 and an $80 \%$ reduction by 2050 [CERI, 2017]. Notwithstanding Mexico's relatively low contribution 
to global GHG emissions, the country has undertaken important efforts to address the problem of climate change. Mexico set priority goals for controlling global warming: a reduction of GHG emissions by $22 \%$ by 2030 and a 50\% reduction in the volume of emissions by 2050 [UNFCCC, 2019.

Carbon capture, utilization, and storage (CCUS) is one of the novel technologies by which carbon dioxide $\left(\mathrm{CO}_{2}\right)$ emissions are captured from sources such as fossil power generation or industrial processes, and either reused or stored. Globally, power and industry account for about $50 \%$ of all GHG emissions, and CCUS is among technologies that can prevent $\mathrm{CO}_{2}$ from entering the atmosphere. While initial development of CCUS technology primarily focused on decarbonizing the power sector, the technology has evolved to include energy-intensive industries such as cement, steel, chemicals, and many other manufacturing sectors.

As of 2019, there are 43 large-scale integrated carbon capture and storage (CCS) or CCUS facilities all over the world (18 projects operating, 5 under construction, and 20 projects at development stage) [Global CCS Institute, 2019]. Those projects are located in several countries, but most are in the U.S. (12) and Canada (7); most captured carbon is used for enhanced oil recovery (EOR). EOR injects CO2 into oil fields to produce additional oil. CO2-EOR has been proved at a number of sites worldwide. In CO2-EOR projects, all of the injected $\mathrm{CO} 2$ either remains sequestered underground or is produced and re-injected. CO2-EOR can effectively lower the carbon intensity of oil production across the value chain.

CO2-EOR is a tertiary oil production process that is used after the primary and secondary oil production phases have been completed and it represents the process of $\mathrm{CO} 2$ injection into depleted or depleting oil and gas fields that causes the oil to run more freely to the producing well. During this process, the injected $\mathrm{CO} 2$ is produced with oil, separated and reinjected, and nearly all of the $\mathrm{CO} 2$ remains securely trapped within the deep geologic formation [NETL, 2010; Melzer, 2012].

CCUS technology development can accelerate deployment of viable options for reducing $\mathrm{CO}_{2}$ emissions related to large point sources while increasing oil production. Despite its great importance, the deployment status of CCUS technology is still at the earliest stage. The investment cost of CCUS is very high; there is also a lack of effective government incentive policies. U.S. Congress approved a tax credit for $\mathrm{CO}_{2}$ utilization and storage known as 45Q in February 2019. The new 45Q tax credit includes no cap on the storage, thereby providing more flexibility for projects that may take years to plan and develop. The new 45Q tax credit increases the subsidy values for the geological storage to $\$ \mathrm{US} 50 / \mathrm{tCO}_{2}$ and for $\mathrm{CO}_{2}$-EOR utilization to \$US $35 / \mathrm{tCO}_{2}$.

The objectives of this study are to evaluate the impact of the $\mathrm{CO}_{2}$-EOR and 45Q tax credits on CCUS investment decision-making and on $\mathrm{CO}_{2}$ emissions reduction in North America. The following sections describe the North America $\mathrm{CO}_{2}$-EOR potential, MARKAL model and scenario definitions, modeling results, and discussion and conclusions.

\section{NORTH AMERICA $\mathrm{CO}_{2}$-EOR POTENTIAL}

\section{United States}

$\mathrm{CO}_{2}$-EOR has been used in the U.S. for decades, beginning in the Permian Basin of West Texas and New Mexico (since the mid-1980s) and expanding to other regions [NETL, 2019]. There were more than 136 active commercial $\mathrm{CO}_{2}$-EOR projects in the U.S. in 2014 and combined, they injected more than 68 million metric tons (Mt) $\mathrm{CO}_{2}$ and produced more than 300 thousand barrels (bbl) of oil per day [Kuuskraa \& Wallace, 2014]. It was estimated that $14 \mathrm{MtCO}_{2}$ from the industrial sector was stored through $\mathrm{CO}_{2}-$ EOR [Kuuskraa \& Wallace, 2014].

To date, the development of $\mathrm{CO}_{2}$ flooding was favored in the Permian Basin; in addition, considerable growth in $\mathrm{CO}_{2}$-EOR is occurring in the Gulf Coast, the Rockies, Oklahoma, and Michigan. The U.S. is a leading country in $\mathrm{CO}_{2}$-EOR, and it is expected that new floods in Wyoming, Kansas, and California will increase the EOR production remarkably. Since the onset of $\mathrm{CO}_{2}-\mathrm{EOR}$, natural $\mathrm{CO}_{2}$ sources were sufficient to provide the $\mathrm{CO}_{2}$ needed for EOR. Today the situation has changed as depletion of the $\mathrm{CO}_{2}$ sources and limitations of the $\mathrm{CO}_{2}$ pipelines are now constricting $\mathrm{CO}_{2}-\mathrm{EOR}$ growth. 
A 2009 study by Advanced Resources International (ARI) assessed the role of $\mathrm{CO}_{2}$-EOR technologies in the future U.S. oil recovery. ARI concluded that providing state production tax incentives, federal investment tax credits, and royalty relief, and establishing low-cost, reliable, $\mathrm{CO}_{2}$ supplies could result in an additional 85 billion barrels (Bbbl) of technically recoverable oil from the $400 \mathrm{Bbbl}$ of oil remaining in large reservoirs across 11 basins [NETL, 2010]. The new Clean Air Task Force (CATF) study on U.S. power sector modeling finds that 45Q federal tax credits for CCS can have a significant impact on $\mathrm{CO}_{2}$ emissions reductions by 2030 [CAFT, 2019].

In $\mathrm{CO}_{2}$-EOR development, the U.S. was followed by Canada and, to some degree, Europe (Turkey, Hungary), Brazil, the United Arab Emirates and China (see Figure 1). These countries also demonstrated that EOR from $\mathrm{CO}_{2}$ floods is a proven technology, and that most of the mature oil fields facing the end of production can extend their lifetime and increase their values by implementing tertiary $\mathrm{CO}_{2}$ floods.

\section{FIGURE 1}

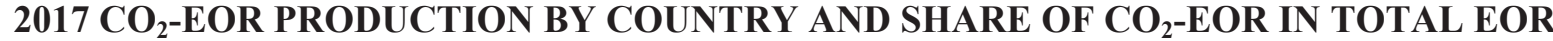 PRODUCTION (RIGHT-HAND WINDOW)}

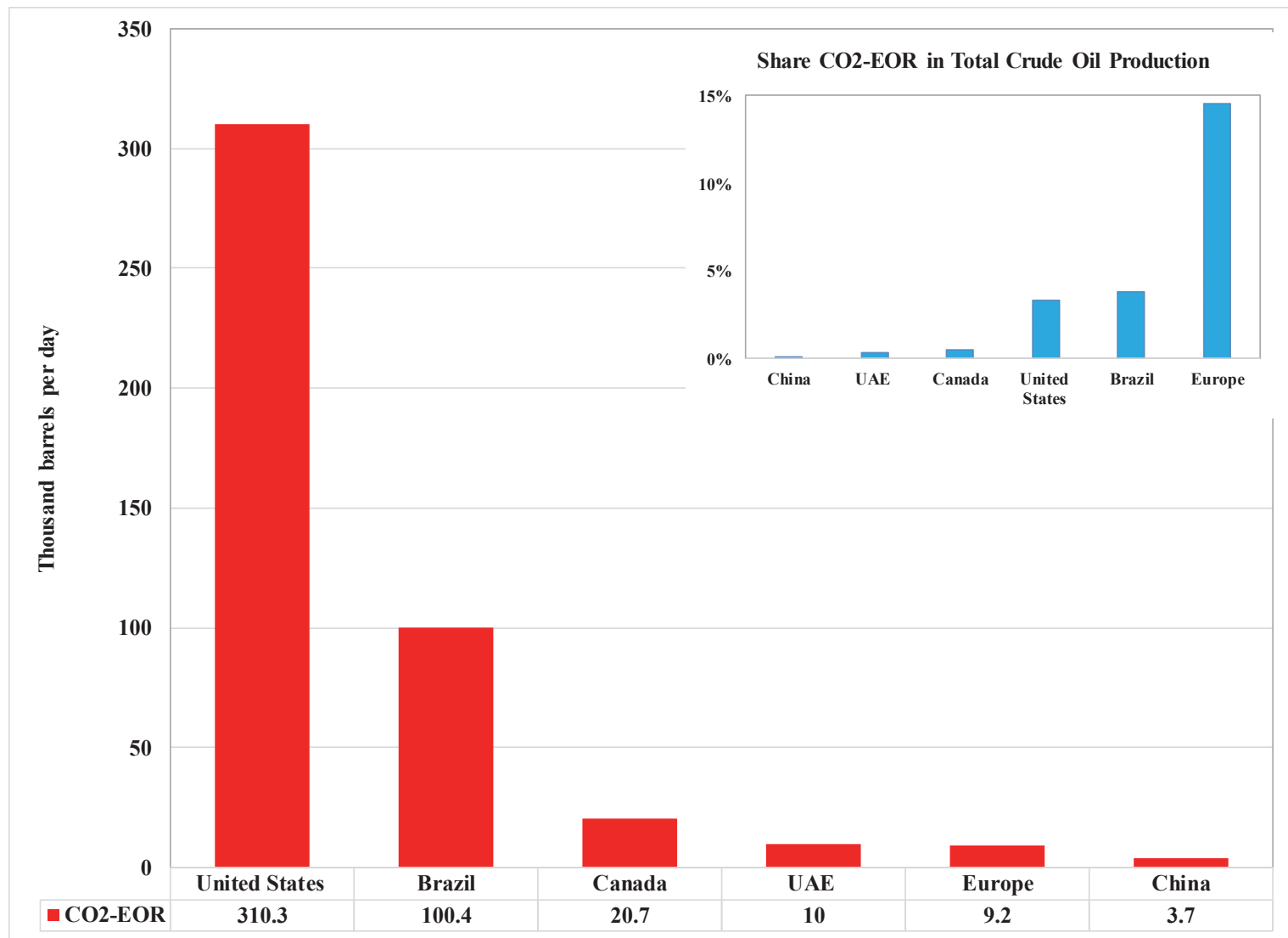

SOURCE: [IEA, 2018]

\section{Canada}

The volume of original oil in place (OOIP) is a key variable in determining the $\mathrm{CO}_{2}$-EOR potential of a reservoir and it is used to estimate how much oil remains as a target for the application of $\mathrm{CO}_{2}$-EOR. In Canada, large field OOIP for $\mathrm{CO}_{2}$-EOR is estimated at $37.6 \mathrm{Bbbl}$ and large field technically recoverable resource (TRR) for $\mathrm{CO}_{2}$-EOR is estimated at 5.7 Bbbl [IEA, 2009; Ahmed \& Meehan, 2016].

The Boundary Dam project, which is the largest $\mathrm{CO}_{2}$-EOR project in Canada, began in 2000 in the Weyburn and Midale fields in Saskatchewan [IEA, 2009; Brown et al., 2017]. This is the largest $\mathrm{CO}_{2}$ storage project in the world and has been used to store around $13 \mathrm{Mt}$ of $\mathrm{CO}_{2}$ to date with $\mathrm{CO}_{2}$ purchased 
from Dakota Gasification Company (a subsidiary of Basin Electric in North Dakota) [Brown et al., 2017]. The $\mathrm{CO}_{2}$-EOR operations resulted in more than a three-fold incremental increase in oil production from $8,000 \mathrm{bbl}$ a day in 2000 to approximately $26,000 \mathrm{bbl}$ a day by 2014, reaching a peak of about 30,000 bbl a day in 2009. By 2016, the Weyburn Field had about $27 \mathrm{MtCO}_{2}$ in the ground, and the Midale Field had slightly over 9 Mt [Brown et al., 2017; Sacuta et al., 2017].

In addition to the projects mentioned above, several pilot projects are running and further $\mathrm{CO}_{2}-$ EOR projects are under development. The extent and maturity of development of $\mathrm{CO}_{2}$-EOR in Canada is lower than in the U.S.

\section{Mexico}

Mexico's large field OOIP for $\mathrm{CO}_{2}$-EOR is estimated at $92.6 \mathrm{Bbbl}$ and large field TRR for $\mathrm{CO}_{2}$-EOR is estimated at $14.1 \mathrm{Bbbl}$, most of which is concentrated in the Gulf of Mexico region [IEA, 2009]. Several factors contributed to difficulties in $\mathrm{CO}_{2}$-EOR in Mexico, including investment constraints and reservoir service capabilities. In March 2014, Mexico launched its CCUS technology roadmap containing recommendations for actions to be taken at a national level up to 2024 focusing on geological storage in deep saline aquifers and EOR projects [Mexican Ministry of Energy, 2014]. This suggests that government investment in research and development (to bring down the cost of capture and infrastructure for sustainable supply of anthropogenic $\mathrm{CO}_{2}$ to close the supply-demand gap) could expand $\mathrm{CO}_{2}$-EOR storage opportunities.

$\mathrm{CO}_{2}$ storage areas have been identified by the North American Carbon Storage Atlas [NETL, 2015], showing that most of the zones are located close to the Gulf of Mexico. The lack of current $\mathrm{CO}_{2}$-EOR projects is largely because anthropogenic $\mathrm{CO}_{2}$ sources are not available or economically feasible in Mexico. For instance, the amount of $\mathrm{CO}_{2}$ available from industrial sources within a 100-kilometer $(\mathrm{km})$ radius of the Villahermosa basin is estimated at about $1 \%$ of the $\mathrm{CO}_{2}$ required for $\mathrm{CO}_{2}$-EOR, while in the Tampico-Misantla basin is it still insufficient at $11 \%$ [Godec, 2011]. It was identified that non-anthropogenic $\mathrm{CO}_{2}$ sources for $\mathrm{CO}_{2}$-EOR projects could be existing industrial and power plants that emit $\mathrm{CO}_{2}$ [Lacy et al., 2013] and also possible new gas-fired power plants in the Gulf of Mexico [González-Díaz et al., 2017].

\section{MARKAL MODEL AND SCENARIOS DEFINITIONS}

MARKet ALlocation (MARKAL) is an integrated-energy-systems modeling platform that can be used to analyze energy, economic, and environmental issues at the global, national, and municipal level over several decades. MARKAL is a bottom-up, dynamic, linear programming optimization model that finds cost-optimal decarbonization pathways within the context of the entire energy system. MARKAL represents energy imports and exports, domestic production of fuels, fuel processing, infrastructures, secondary energy carriers, end-use technologies, and energy service demands of the entire economy. MARKAL does not contain a built-in database, so the user is obliged to enter input parameters. In this study, the publicly available EPAUS9r2017 database for the U.S. energy system had been adopted and modified. EPAUS9r2017 (with the U.S. Census regions represented) was created by the Environmental Protection Agency (EPA) in 2017 to model changes in the U.S. energy sector through 2055. We extended EPAUS9r2017 and included Canadian and Mexican energy systems as two new regions.

Each of the 11 regions (9 of the U.S. Census regions, Canada, and Mexico) was modeled as an independent energy system with different regional costs, resource availability, existing capacity, and end-use demands. Regions are connected through a trade network that allows transmission of electricity and transport of gas and fuels. Electricity transmission is constrained to reflect existing regional connections between North American Electric Reliability Corporation (NERC) regions as closely as possible. Given the significant role of the U.S., Canada, and Mexico on the world energy system, our results represent an important contribution to the study of global energy trends.

We included $\mathrm{CO}_{2}$-EOR technology in the database. The following assumptions and limitations are related to $\mathrm{CO}_{2}$-EOR in MARKAL: 
- Natural sources of $\mathrm{CO}_{2}$ and industrial sources from gas processing plants, a host of nitrogen, hydrogen, fertilizer etc., were included into the model.

- There is no published work in the literature regarding potential of Canadian natural $\mathrm{CO}_{2}$ sources to the knowledge of the authors, so natural sources of $\mathrm{CO}_{2}$ in Canada were not included in the model. ${ }^{1}$

- $\mathrm{CO}_{2}$-EOR projects are presented at the regional levels (not at the project or reservoir levels).

- The volume of $\mathrm{CO}_{2}$ recycled for injection was not included. Instead "fresh" $\mathrm{CO}_{2}$ usage rates were applied (fresh $\mathrm{CO}_{2}$ and oil produced ratio). Fresh $\mathrm{CO}_{2}$ usage rates can be calculated as $\mathrm{CO}_{2}$ Purchased and Oil Produced ratio or $\mathrm{CO}_{2}$ Injected minus $\mathrm{CO}_{2}$ Recycled and Oil Produced ratio (see details on fresh vs. "injected" $\mathrm{CO}_{2}$ in [Melzer, 2012]).

- The difference between the volume of $\mathrm{CO}_{2}$ Injected and $\mathrm{CO}_{2}$ Produced represents the volume of $\mathrm{CO}_{2}$ permanently stored in the reservoir.

- We assumed $\mathrm{CO}_{2}$-EOR recovery efficiency of 20\% (from operational evidence from the Permian basin) suggests feasibility [Godec et al., 2011].

\section{FIGURE 2 \\ $\mathrm{CO}_{2}$-EOR MODULE IN MARKAL MODEL AND RELATIONSHIP WITH TECHNOLOGY GROUPS}

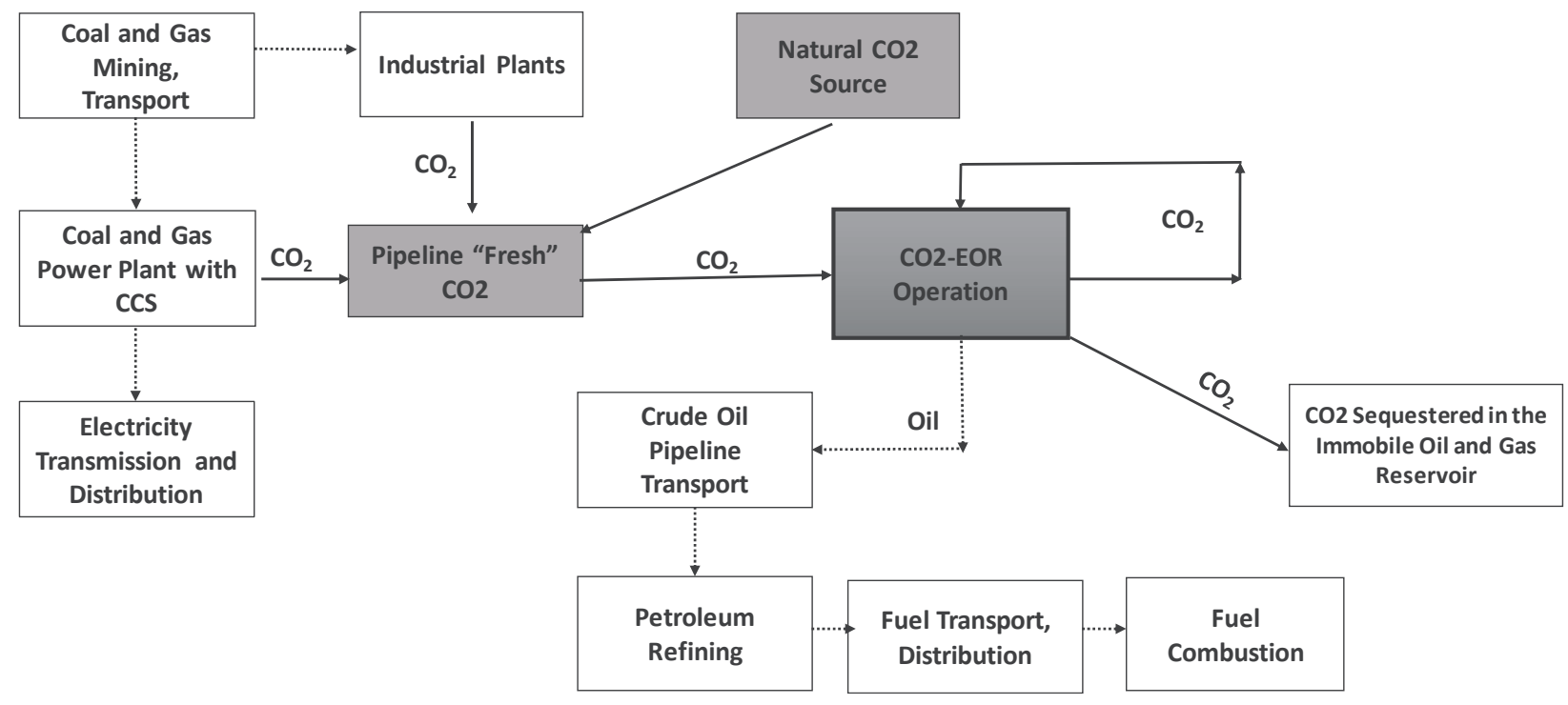

Figure 2 shows a simplified $\mathrm{CO}_{2}$-EOR module that we developed for our study in MARKAL (marked by grey) and its relationship with other technologies groups in the model. During $\mathrm{CO}_{2}$-EOR, a large percentage of the originally injected $\mathrm{CO}_{2}$ gets trapped in the geologic formation and the trapping continues as long as the $\mathrm{CO}_{2}$ is injected. As the result of this "incidental" sequestration, the $\mathrm{CO}_{2}$ that is produced should be recycled (captured, compressed, and continuously added to newly purchased fresh $\mathrm{CO}_{2}$ ) for EOR operations to continue. Because of the effective "closed loop," the experience of the industry to date is that $90-95 \%$ of the purchased $\mathrm{CO}_{2}$ remains securely trapped within the deep geologic formation. As naturally occurring $\mathrm{CO}_{2}$ can be permanently trapped safely in many geologic situations, $\mathrm{CO}_{2}$ from EOR can be permanently trapped as well.

However, not every subsurface situation will provide the needed security and effective storage sites; geologic regimes with certain attributes are needed to assure the $\mathrm{CO}_{2}$ will stay in the subsurface and not migrate toward the surface. We didn't address these safety issues in our study and assumed, per se, the selection of sites is best practices in the oil and gas industry and that $\mathrm{CO}_{2}$ delivered to the EOR facility 
will be contained within the reservoir and in closed-loop recycle systems, and, thus kept out of the atmosphere.

We examined $\mathrm{CO}_{2}$ emissions and energy system technologies deployments under the six scenarios (see Table 1 for scenario names and definitions).

\section{TABLE 1 SCENARIO DEFINITIONS}

\begin{tabular}{|c|c|}
\hline Scenario Name & Scenario Definition \\
\hline Reference & Reference \\
\hline CCUS indef life & $\begin{array}{l}\text { Reference scenario with } \mathrm{CO}_{2} \text {-EOR option in Canada and Mexico, } \\
\text { and } 45 \mathrm{Q} \text { tax credits in } 2020-2050 \text { in the U.S. Tax credit of } \$ \mathrm{US} 30 \\
\text { per tonne of } \mathrm{CO}_{2} \text { for anthropogenic } \mathrm{CO}_{2} \text { going to EOR, and } \$ \mathrm{US} \\
50 \text { per tonne if going to straight storage }\end{array}$ \\
\hline CCUS high credit & $\begin{array}{l}\text { CCUS indef life with higher credits for } 45 \mathrm{Q} \text {. Tax credit of } \$ \mathrm{US} 50 \\
\text { per tonne of } \mathrm{CO}_{2} \text { for anthropogenic } \mathrm{CO}_{2} \text { going to EOR, and } \$ \mathrm{US} \\
75 \text { per tonne if going to straight storage }\end{array}$ \\
\hline CCUS high oil price & $\begin{array}{l}\text { High oil prices and with } \mathrm{CO}_{2} \text {-EOR in Canada and Mexico, and } \\
45 \mathrm{Q} \text { in the U.S. Oil prices are consistent with AEO } 2017 \text { low oil } \\
\text { reserves scenario }\end{array}$ \\
\hline $\begin{array}{l}\text { CCUS indef life+carbon } \\
\text { price }\end{array}$ & $\begin{array}{l}\text { Carbon policy (scenario with environmental constraints): carbon } \\
\text { taxes at \$US } 35 / \text { tonne starting } 2020 \text { and increasing at } 5 \% \text { per year } \\
\text { until 2055. This scenario includes } \mathrm{CO}_{2} \text {-EOR option in Canada and } \\
\text { Mexico, and 45Q tax credit option in the U.S. }\end{array}$ \\
\hline CCUS NA policy & CCUS indef life with 45Q in Canada and Mexico \\
\hline
\end{tabular}

\section{MODELING RESULTS}

\section{System-Wide $\mathrm{CO}_{2}$ Emissions}

Figure 3 through Figure 5 show North America's system-wide, power sector $\mathrm{CO}_{2}$ emissions (historical and scenario projections). In 2015-2030, energy system decarbonization can be observed in the U.S. and Canada in all scenarios as a result of the energy use exchange to lower carbon technologies such as natural gas or energy efficiency improvements (Figure 3 and Figure 4). 
FIGURE 3

\section{U.S. $\mathrm{CO}_{2}$ EMISSIONS BY SCENARIO: ENERGY SYSTEM AND POWER SECTOR} (LEFT WINDOW)

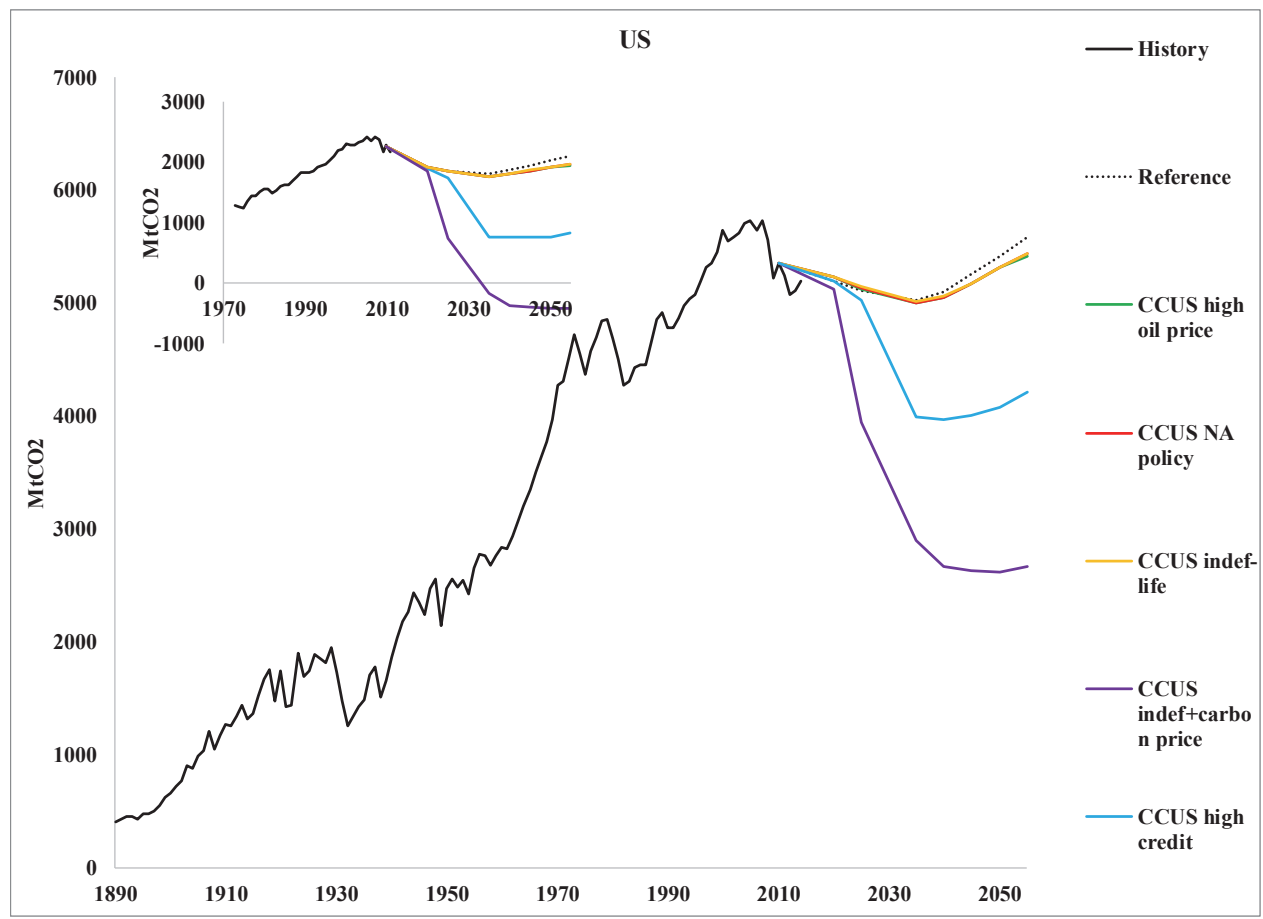

SOURCES: EIA (2019a); CDIAC (2019)

FIGURE 4

CANADA $\mathrm{CO}_{2}$ EMISSIONS BY SCENARIO: ENERGY SYSTEM AND POWER SECTOR (LEFT WINDOW)

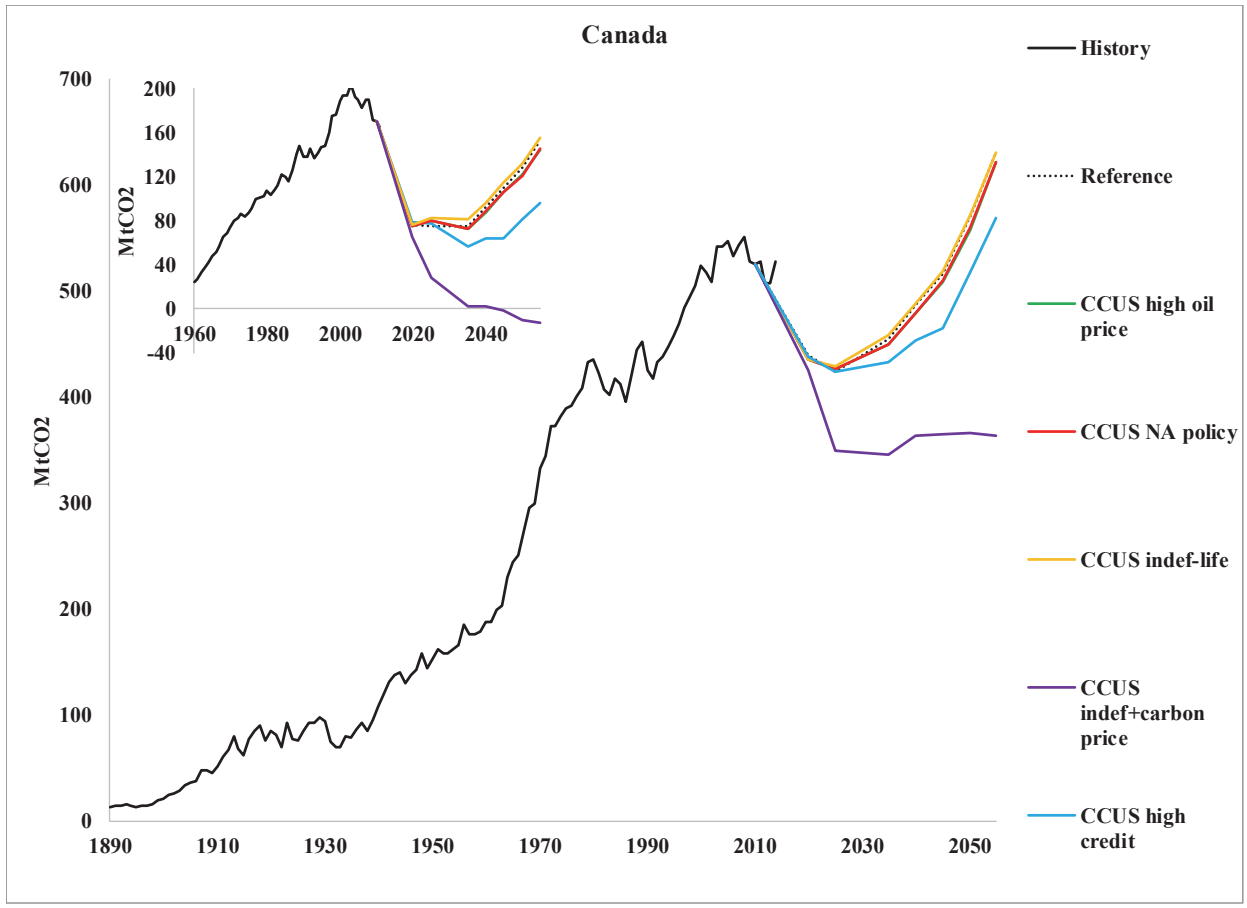

SOURCES: THE WORLD BANK (2019); CDIAC (2019) 
System-wide $\mathrm{CO}_{2}$ emissions are projected to fall from 2015 through 2030 with $8 \%$ decline in the U.S. in the Reference, CCUS indef life, CCUS high oil price, and CCUS NA policy scenarios; $20 \%$ decline in the CCUS high credit scenario; and $36 \%$ decline in the CCUS indef life+carbon price scenario. In Canada, in 2015-2030, system-wide $\mathrm{CO}_{2}$ emissions decline by $8 \%$ in the Reference, CCUS indef life, and CCUS high oil price scenarios; $11 \%$ in CCUS NA policy scenarios and CCUS high credit scenarios; and $28 \%$ in the scenario with environmental constraint. Thus, in the U.S. and Canada, system-wide short-term $\mathrm{CO}_{2}$ emissions are projected to decline even without climate policies.

However, $\mathrm{CO}_{2}$ emissions start to increase in 2030 in the Reference, CCUS indef life, CCUS high oil price, and CCUS NA policy scenarios; the U.S. system-wide $\mathrm{CO}_{2}$ is about $3 \%$ lower and in Canada about $29 \%$ higher by 2050 than in 2015 . The deepest $\mathrm{CO}_{2}$ reduction- $52 \%$ in the U.S. and $23 \%$ in Canada by 2050 - can be observed only in the CCUS indef life+carbon price scenario. Still, without carbon policy, but under higher 45Q tax credits assumptions, in the U.S. $\mathrm{CO}_{2}$ emissions decline more than $25 \%$ from 2015 to 2050.

Historical observation shows that total $\mathrm{CO}_{2}$ emissions in Mexico start to decrease in 2012 at about 2\% annual rates (Figure 5). Our modeling results display a system-wide $\mathrm{CO}_{2}$ emissions decrease until 2020 and increase afterwards through 2050 in all scenarios, excluding the scenario with environmental constraints. By 2030, system-wide $\mathrm{CO}_{2}$ emissions are 5-10\% higher than in 2015 in the Reference, CCUS indef life, CCUS high oil price, and CCUS NA policy scenarios. By 2030, Mexico system-wide $\mathrm{CO}_{2}$ emissions in the CCUS indef life+carbon price scenario are 38\% lower than in 2015 and increase afterwards; by $2050, \mathrm{CO}_{2}$ is $12 \%$ lower than in 2015 .

\section{FIGURE 5 \\ MEXICO $\mathrm{CO}_{2}$ EMISSIONS BY SCENARIO: ENERGY SYSTEM AND POWER SECTOR (LEFT WINDOW)}

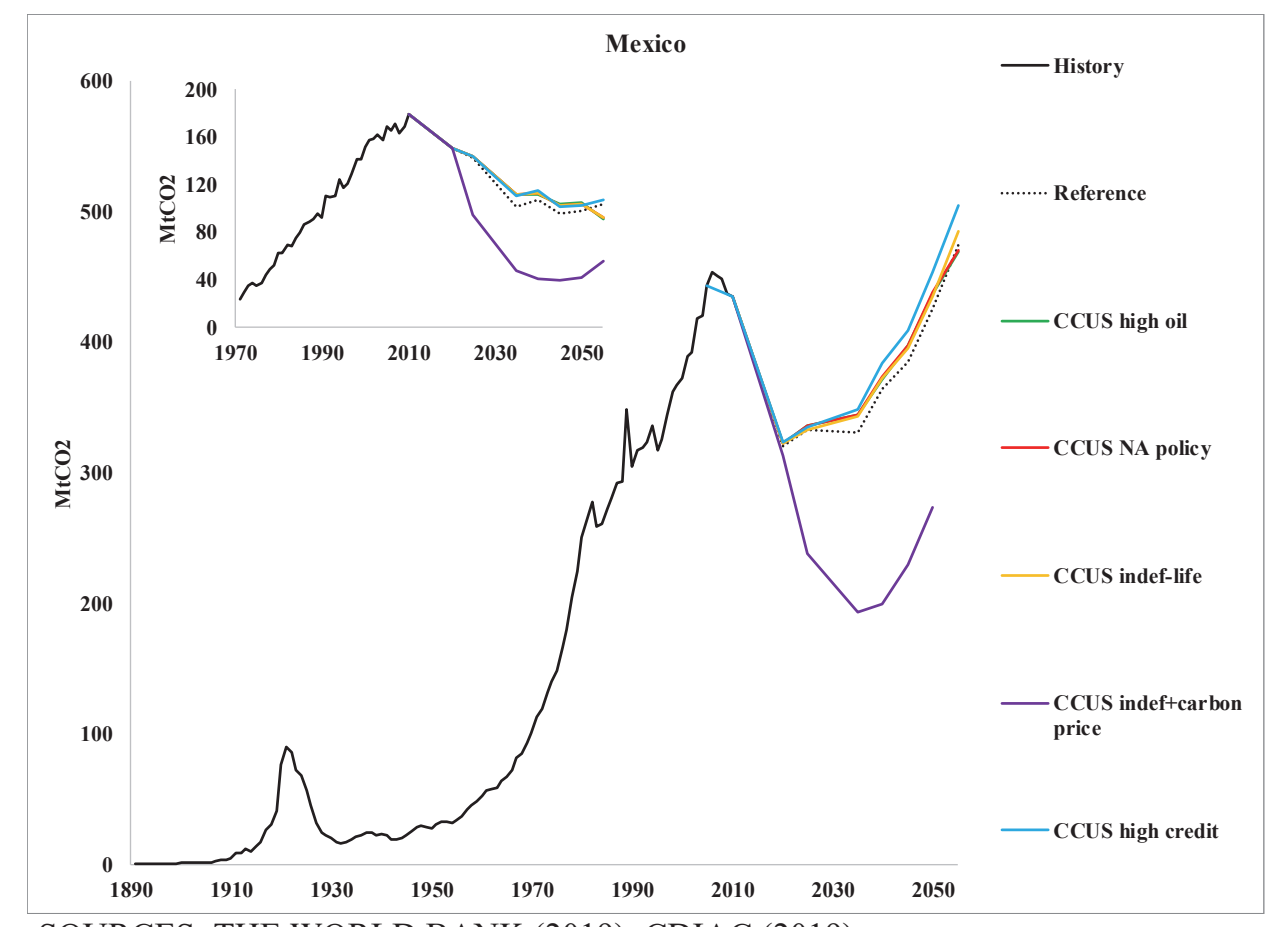

SOURCES: THE WORLD BANK (2019); CDIAC (2019)

System-wide $\mathrm{CO}_{2}$ emissions in North America (the U.S., Canada, Mexico) are projected to decrease in the short-term, by 2030, in all scenarios: 36\% reduction below the 2015 in the CCUS indef life+carbon scenario, $18 \%$ reduction in the CCUS high credit scenario, and 7\% reduction in all other scenarios. In the long-term, by 2050 , decarbonization is observed in only two scenarios: $48 \%$ reduction below the 2015 in 
the CCUS indef life+carbon scenario and 19\% reduction in the CCUS high credit scenario. In all other scenarios, power sector $\mathrm{CO}_{2}$ is only 8-12\% lower than 2015 levels by 2050.

\section{Power Sector $\mathrm{CO}_{2}$ Emissions}

U.S. power generation $\mathrm{CO}_{2}$ emissions fell more than 20\% from 2007-2015, while system-wide $\mathrm{CO}_{2}$ emissions have decreased by $12 \%$ over the same time period (see Figure 3 ). A major contributing factor to lower $\mathrm{CO}_{2}$ emissions from the power sector is increased generation from natural gas that replaced generation from coal, largely due to lower gas prices resulting from increased shale gas availability. Similarly, $\mathrm{CO}_{2}$ emissions from electricity generation are projected to be $19 \%$ below the 2015 level by 2030 in the Reference, CCUS indef life, CCUS high oil price, and CCUS NA policy scenarios; 49\% below in the CCUS high credit scenario; and $84 \%$ below in the $\mathrm{CO}_{2}$ taxation scenario.

Short-term $\mathrm{CO}_{2}$ reduction in the power generation sector in Canada is greater than in the U.S.: 34 $40 \%$ below the 2015 level by 2030 in the Reference, CCUS indef life, CCUS high oil price, and CCUS NA policy scenarios; $48 \%$ below in the CCUS high credit scenario; and $93 \%$ in the $\mathrm{CO}_{2}$ taxation scenario (Figure 4).

After 2030, the U.S. power sector $\mathrm{CO}_{2}$ emissions in the Reference, CCUS indef life, CCUS high oil price, and CCUS NA policy scenarios start to stabilize with an increase afterwards and are projected to be $8-12 \%$ below the 2015 level by 2050 . In the CCUS high credit scenario, $\mathrm{CO}_{2}$ emissions are $65 \%$ below the 2015 level by 2050. Power sector $\mathrm{CO}_{2}$ emissions become net-negative in the CCUS indef life+carbon price scenario due to biomass integrated gasification combined cycle (IGCC) with CCS deployment with about $120 \%$ reduction by 2050 .

In the long-term, by 2050, power sector decarbonization rates in Canada are lower than in the U.S.: $\mathrm{CO}_{2}$ emissions in the Reference, CCUS indef life, CCUS high oil price, and CCUS NA policy scenarios are $8-17 \%$ higher the 2015 level by $2050 . \mathrm{CO}_{2}$ emissions become net-negative in the CCUS indef life+carbon price scenario by 2050 with about $109 \%$ reduction by 2050 below the 2015 level by 2050 . In the CCUS high credit scenario, power $\mathrm{CO}_{2}$ emissions are 28\% below the 2015 level.

Remarkably, power sector $\mathrm{CO}_{2}$ emissions in Mexico are in decline with about 30\% reduction below the 2015 level by 2050 in all scenarios excluding the scenario with $\mathrm{CO}_{2}$ taxation. $\mathrm{CO}_{2}$ taxes lead to $70 \%$ emissions reduction by 2050 in Mexico (Figure 5).

Electricity generation $\mathrm{CO}_{2}$ emissions in North America are projected to decrease in the mid-term, by 2030, in all scenarios: 83\% reduction below the 2015 in the CCUS indef life+carbon scenario, $47 \%$ reduction in the CCUS high credit scenario, and 19\% reduction in all other scenarios. In the long-term, by 2050, deep power sector decarbonization is observed in only two scenarios: 116\% reduction below 2015 levels in the CCUS indef life+carbon scenario and 61\% reduction in the CCUS high credit scenario. In all other scenarios, power sector $\mathrm{CO}_{2}$ is only 8-12\% lower than in 2015 by 2050 .

\section{Power Sector Technological Changes}

Modeling $\mathrm{CO}_{2}$ emissions results indicate that most reductions occur primarily in power generation; therefore, analysis of technological change in electricity sector is valuable. The U.S., Canada, and Mexico power sector technologies mixes are presented in Figure 6 through Figure 9 for all six scenarios.

\section{United States}

In the U.S., fossil fuels are the largest source of energy for electricity generation. Natural gas and coal were the largest source - about 33\% each-of U.S. electricity generation in 2015. Nuclear energy provided about $19.6 \%$ of U.S. electricity generation in 2015 . Renewable energy sources provide $17 \%$ of U.S. electricity in 2015: hydropower plants produced about 6\%, wind about 5\%, and solar energy about $1 \%$ [EIA, 2019b].

In the U.S., in the Reference, CCUS indef life, CCUS high oil price, and CCUS NA policy scenarios (Figure 6), most conventional coal plants remained active through 2050 though their share in total electricity generation is decreasing. By 2050 , about $43 \%$ of the electricity generated is from natural gas, $24 \%$ from coal, and $17 \%$ from renewables. There is some CCS deployment in the scenarios with $45 \mathrm{Q}$ : 
natural gas and coal plants retrofit by 2035 and new IGCC and natural gas combined cycle (NGCC) plants with CCS by 2045. Results show that high oil prices do not affect much of the U.S. power generation mix.

In the CCUS high credit scenario, new NGCC with CCS deployment starts by 2035 and new IGCC with CCS starts by 2050, with coal's share of power generation, primarily IGCC CCS, reaching 51\%. By 2050 , about $40 \%$ of the electricity is generated from natural gas (11\% from NGCC CCS), $14 \%$ from nuclear, and $16 \%$ from renewables in the CCUS high oil price scenario. In the scenario with $\mathrm{CO}_{2}$ taxation, IGCC CCS and NGCC CCS deployments start by 2025 and biomass IGCC with CCS starts by 2030. By 2050 , about $65 \%$ of the electricity is produced by power plants with CCS, $18 \%$ from renewables, and $13 \%$ from nuclear. In addition, total electricity generation in the CCUS indef life+carbon price scenario is about $17 \%$ higher than in the Reference scenario by 2050.

\section{FIGURE 6}

\section{U.S. ELECTRICITY GENERATION MIX BY SCENARIO}
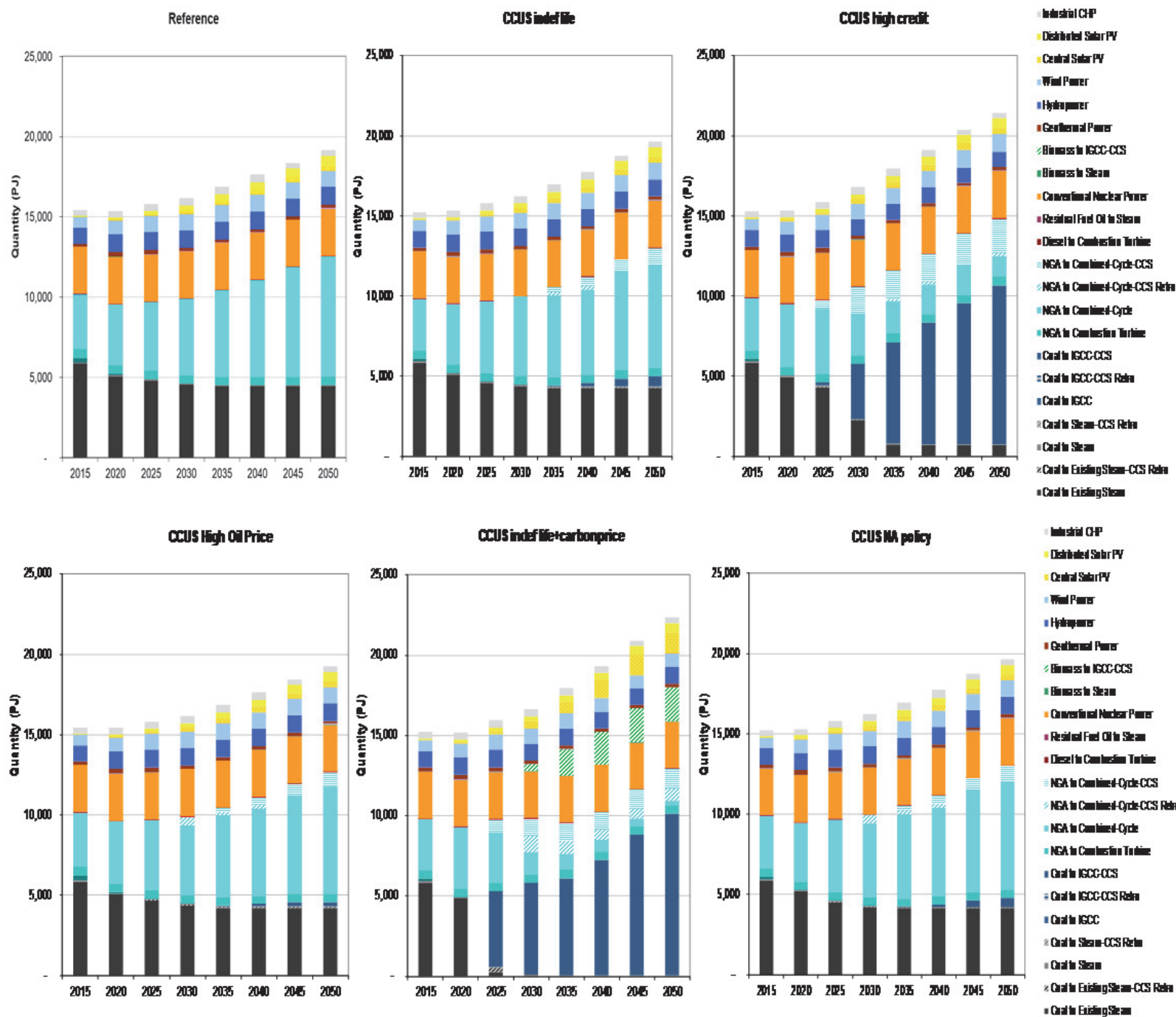

orath Gisightiva 


\section{Canada}

Electricity in Canada is generated from a less diversified mix of sources than in the U.S. The majority of supply comes from hydropower (more than 50\%), while nuclear, coal and, to a lesser extent, natural gas provides the remaining production (Figure 7). In 2015, coal, nuclear power, and natural gas contributed about $14 \%$ each. Small volumes of electricity were produced from renewables and wasteabout 5\%. The Canadian electricity system is part of an integrated North American electricity grid. Canada is a net exporter of electricity to the U.S. and in 2015, net exports of electricity to the U.S. were about 60 Terawatt-hours (TWh) [NEB, 2019].

The projections of electricity mixes sources do not greatly vary in the Reference, CCUS indef life, and CCUS high oil price scenarios. Total hydropower production is about $43 \%$ of total power generation by 2050. Electricity generation from natural gas increases significantly and is about $40 \%$ by 2050 . Electricity production from coal makes a negligible contribution after 2020 in all scenarios excluding CCUS high oil price and CCUS NA policy because higher oil prices and tax credits for $\mathrm{CO}_{2}$-EOR stimulate IGCC CCS deployment after 2030. In two scenarios (CCUS high credit and CCUS indef life+carbon price), total electricity generation is 30\% lower than in the Reference scenario by 2050 because deployment of more efficient end-use technologies and electricity imports from the U.S. are more economically attractive than increasing renewable or nuclear capacities.

\section{FIGURE 7}

\section{CANADA ELECTRICITY GENERATION MIX BY SCENARIO}
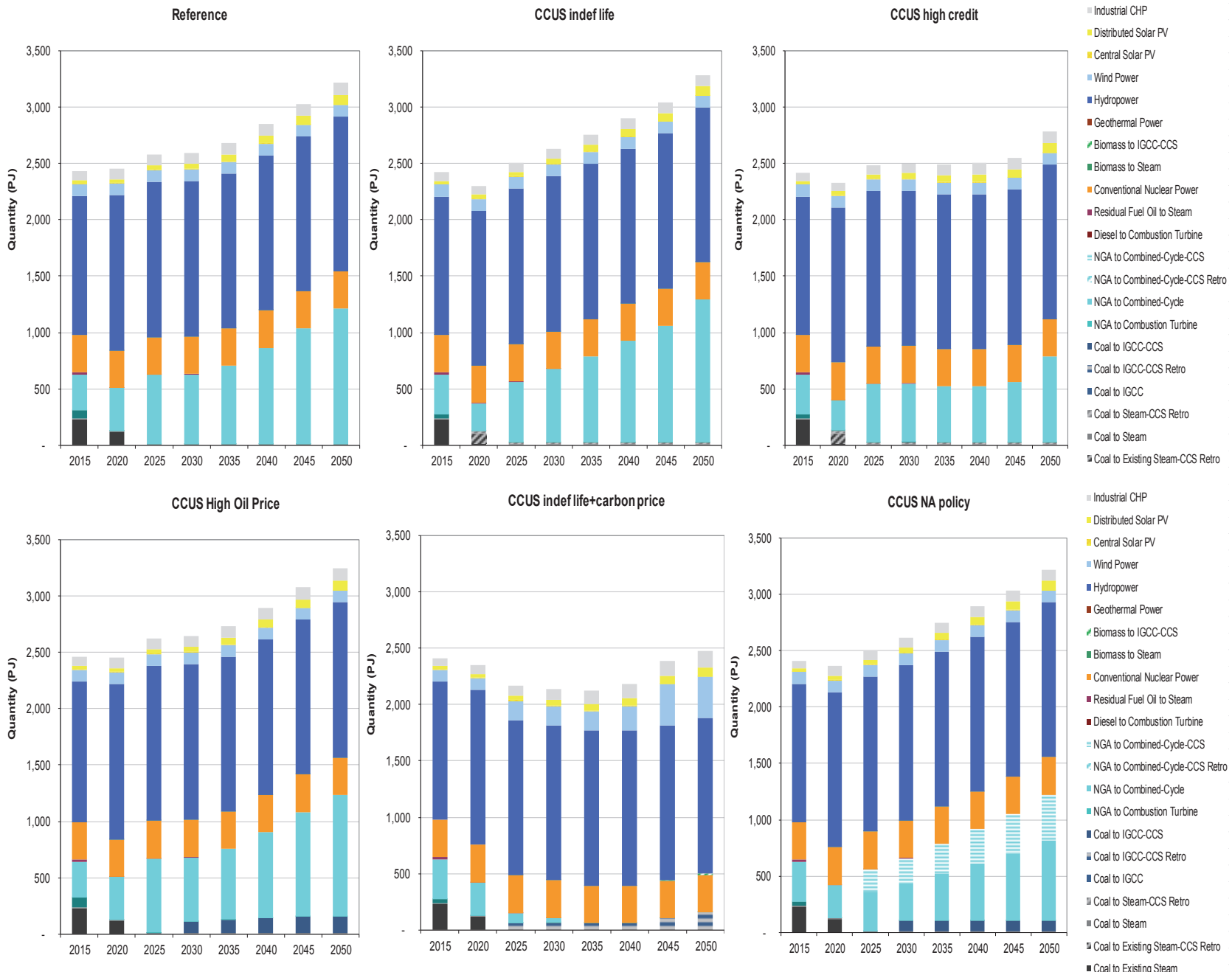


\section{Mexico}

Mexico generated an estimated $310 \mathrm{TWh}$ of electricity in 2015, an increase of $21 \%$ from 2005. Fossil-fuel power plants provided $72 \%$ of Mexico's electricity capacity and $80 \%$ of electricity generation in 2015 [EIA, 2016]. In 2015, the share of electricity generation from nuclear was 3.8\%, from hydro $10.4 \%$, and from other renewables 3.5\% (Figure 8). U.S.-Mexico electricity trade is small compared to the electricity trade between the U.S. and Canada. Natural gas used for electricity generation in Mexico has risen rapidly since 2005 and had reached $60 \%$ of total production by 2015 , as price and availability have made it a more economic fuel source. Coal represents only $7 \%$ of total electricity generation. Mexico is a net importer of coal, supplying about $80 \%$ of its coal demand domestically.

According to scenario projections, fossil fuels will play an important role in power generation, though their share is projected to decrease from $80 \%$ in 2015 to $40-53 \%$ by 2050 in Mexico. In all scenarios (Figure 8), most conventional coal plants remain active through 2050 and in the majority are retrofitted with CCS by 2030-2035. There is NGCC CCS deployment by 2050 in the CCUS indef life and CCUS high credit scenarios. In the CCUS high oil price scenario, NGCC CCS deployment starts by 2040 to support $\mathrm{CO}_{2}$-EOR projects. Implementation of 45Q policy in Mexico resulted in NGCC CCS deployment and conventional coal plants retrofits by 2035 .

\section{FIGURE 8 \\ MEXICO ELECTRICITY GENERATION MIX BY SCENARIO}
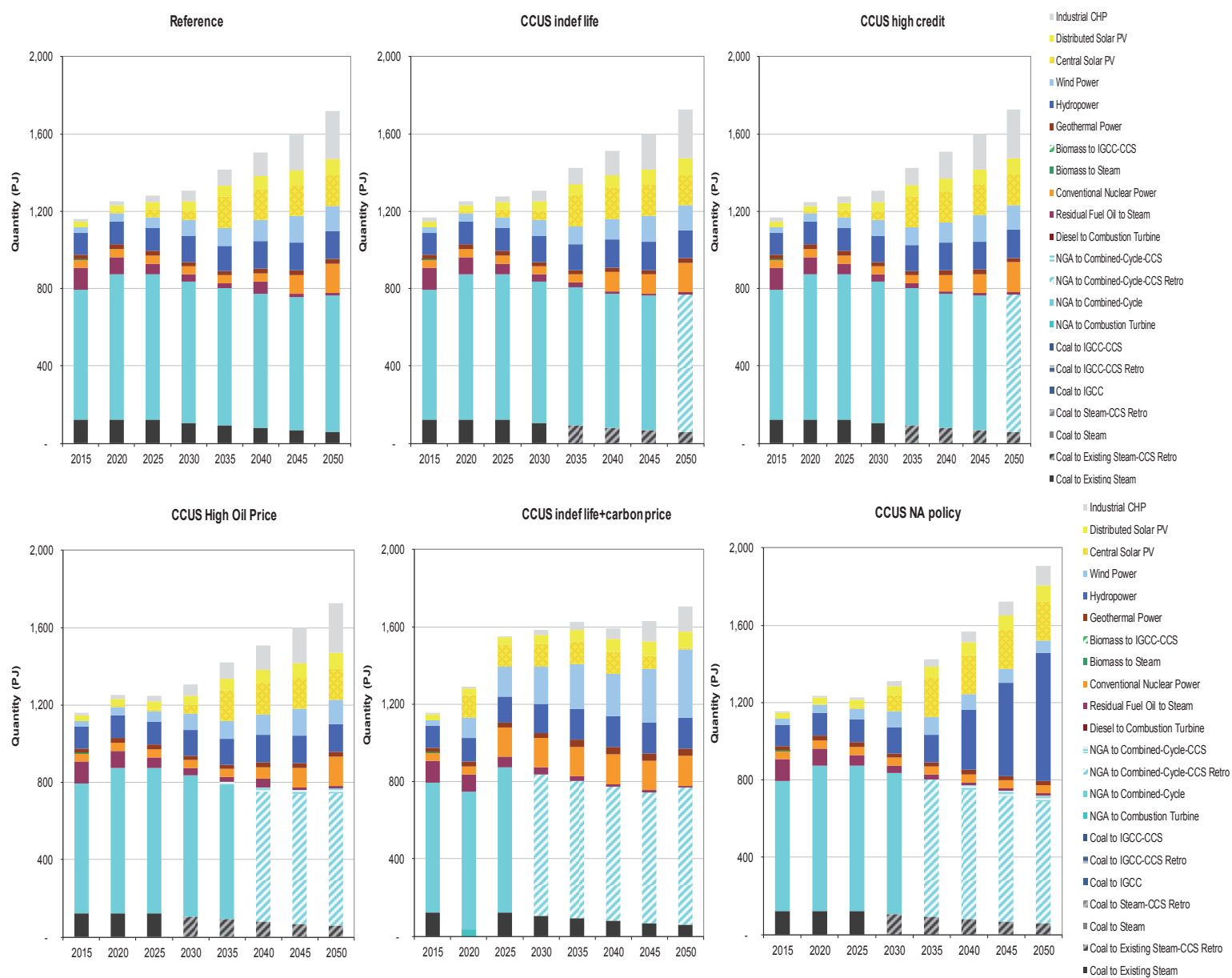
In the $\mathrm{CO}_{2}$ taxation scenario, deployment of NGCC CCS started earlier than in other scenarios, by 2030; there is no CCS retrofit in conventional coal plants. In the Reference scenario, by 2050 , about $48 \%$ of the electricity is generated from natural gas, $4 \%$ from coal, and $37 \%$ from renewables $(10 \%$ from hydro). In the $\mathrm{CO}_{2}$ taxation scenario, about $36 \%$ of the electricity is generated from natural gas with CCS, $3 \%$ from coal, and $57 \%$ from renewables (37\% from hydro) by 2050 . Thus, natural gas plants (with and without CCS) and renewables play a more important role in future power generation in Mexico.

\section{DISCUSSION AND CONCLUSIONS}

Though uncertainties remain regarding technological change, economic growth, and political agendas that affect scenario projections, the following conclusions emerge from this study:

- Analysis reveals that there clearly is momentum toward decarbonization in the short-term future: less efficient coal power plants are disappearing from the generation portfolios and a main factor in the observed decarbonization is the switching of coal-based generation to natural gas. However, the emissions of a large natural gas-based fleet create issues later in the forecast period without climate policies.

- Reaching 2015 United Nations Climate Change Conference (COP21) 2030 goals is problematic for the U.S. and Canada; reaching 2050 goals is problematic for all of North America without climate policies that are stronger than $\mathrm{CO}_{2}$ taxation. Delay in decarbonization might imply the need for more radical intervention, e.g., a massive deployment of negative emissions technologies.

- Analysis finds that successful CCUS development depends on regulatory frameworks, such as $45 \mathrm{Q}$ tax credits. However, project finance remains the most challenging piece without incentives to encourage CCUS deployment.

The main finding of this study is that it is technically feasible to achieve about $50 \% \mathrm{CO}_{2}$ emissions reduction below the 2015 levels by 2050 in North America through $\mathrm{CO}_{2}$ taxation and deployment of existing or near-commercially available technologies. These emissions reductions are primarily achieved through high levels of electricity sector decarbonization in the U.S. and Mexico, electrification of end uses in the U.S., and energy efficiency improvements in Canada. The results show that $\mathrm{CO}_{2}$ taxation policy accelerates the deployment of CCUS in the U.S. and Mexico, but to a lesser degree in Canada, where the share of renewables and, predominantly, hydro is significantly higher than in the U.S. and Mexico. Thus, the $\mathrm{CO}_{2}$ taxation scenario shows that the North America economies' decarbonization over the next 35 years requires a large transformation of the energy system.

The results show that $\mathrm{CO}_{2}$-EOR technologies deployment doesn't have an impact on energy-wide $\mathrm{CO}_{2}$ emissions reductions, though some impact on power sector $\mathrm{CO}_{2}$ can be observed. Modeling results demonstrate that power generation mixes are largely dependent on $\mathrm{CO}_{2}$ constraints and, to some degree, on $\mathrm{CO}_{2}$-EOR policies. Though CCUS deployment can be seen in all of North America, the highest level of deployment is in the U.S., and this is a result of 45Q tax credits policies.

$\mathrm{CO}_{2}$-EOR is not a new phenomenon, and commercial, profitable $\mathrm{CO}_{2}$-EOR projects have existed for more than 30 years in the U.S. $\mathrm{CO}_{2}$-EOR has been deployed extensively in the Permian Basin of West Texas and a few other areas in the U.S. since the mid-1980s. An extensive $\mathrm{CO}_{2}$ pipeline network has been established to deliver the $\mathrm{CO}_{2}$ required by these projects, often over long distances, primarily from highpurity and low-cost natural sources of $\mathrm{CO}_{2}$. However, 45Q tax credit policies make $\mathrm{CO}_{2}$ from industrial and power plants sources more economically attractive.

Including similar tax credit policies into scenarios for Mexico and Canada show that Mexico is more responsive to CCUS deployment than Canada. The reason is that an optimal candidate for $\mathrm{CO}_{2}$-EOR project is a mature, declining, water-flooded oil field; there is higher reserve base for $\mathrm{CO}_{2}$-EOR projects in Mexico than in Canada. In addition, for the first decades of $\mathrm{CO}_{2}-\mathrm{EOR}$, the natural $\mathrm{CO}_{2}$ source usually provides the $\mathrm{CO}_{2}$ needed for EOR, but there are few small $\mathrm{CO}_{2}$ fields in existence in Canada and the $\mathrm{CO}_{2}$ deliverability from these fields would be inadequate for $\mathrm{CO}_{2}$-EOR projects. Thus, in Mexico, with 
depleted oil fields and significant natural $\mathrm{CO}_{2}$ sources, only pipeline limitations would likely constrict EOR growth.

The major barrier to CCUS deployment is that currently there is no value placed on sequestered $\mathrm{CO}_{2}$ emissions; $\mathrm{CO}_{2}$ that is injected for storage is considered waste, not a commodity. In addition, CCS power plants are not commercially competitive in today's power generation market due to high costs. Combining CCS with EOR could provide a critical financial incentive to facilitate development of CCS projects in the near term.

There are no specific technological barriers or challenges in transitioning and converting a pure $\mathrm{CO}_{2}-$ EOR operation into a $\mathrm{CO}_{2}$ storage operation but there are a number of legal, regulatory, and economic differences that must be addressed if an EOR project is to serve as a CCS project.

\section{ENDNOTES}

1. There are a few small $\mathrm{CO} 2$ fields that exist in the southwest corner of Saskatchewan. The CO2 deliverability from these fields would be inadequate for CO2-EOR projects [Brown, et al., 2017].

2. Section 45Q is a part of the U.S. Congress Bipartisan Budget Act of 2018. Section 45Q provides a performance-based tax credit for carbon capture projects of \$US 30 per metric ton of $\mathrm{CO} 2$ for anthropogenic CO2 going to EOR, and \$US 50 per metric ton if going to straight storage. The credit is linked to the installation and use of carbon capture equipment on industrial sources, gas or coal power plants, or facilities that would directly remove $\mathrm{CO} 2$ from the atmosphere. The captured carbon can then be utilized in the development of products or EOR, or it can be disposed of as waste in deep saline geologic formations. There are several conditions to the credit, including that it applies to new plants that commence construction before 2024 and there is a 12-year time limit on the tax credits [CATF, 2019].

\section{REFERENCES}

Ahmed U., \& Meehan D.N. (2016). Unconventional oil and gas resources: exploitation and development. Boca Raton: Taylor \& Francis.

Brown K., Whittaker S., Wilson M., Srisang W., Smithson H., \& Tontiwachwuthikul P. (2017). The history and development of the IEA GHG Weyburn-Midale $\mathrm{CO}_{2}$ Monitoring and Storage Project in Saskatchewan, Canada (the world largest $\mathrm{CO}_{2}$ for EOR and CCS program). Petroleum, 3(1). doi: 10.1016/j.petlm.2016.12.002.

CATF. (2019). Carbon Capture \& Storage in the United States Power Sector. Retrieved from Clean Air Task Force: https://www.catf.us/resource/45q-ccs-analysis/

CDIAC. (2019). Carbon Dioxide Information Analysis Center, Oak Ridge National Laboratory, Oak Ridge, Tennessee. Retrieved from Carbon Dioxide Information Analysis Center: http://cdiac.essdive.lbl.gov/ft/ndp030/nation.1751_2014.ems

CERI. (2017). Greenhouse Gas Emissions Reductions in Canada Trough Electrification of Energy Services, Canadian Energy Research Institute, Study No. 162. Retrieved from Natural Resources Canada: https://www.nrcan.gc.ca/sites/www.nrcan.gc.ca/files/energy/energyresources/CERI_Study_162_Full_Report.pdf

Demchuk, M., \& Weyburn, T.L. (2008). Spinning Straw into Black Gold: Enhanced Oil Recovery Using Carbon Dioxide, Testimony. U.S. House of Representatives. Washington, DC.

Diringer, E. (2017). Let Trump claim a better deal on climate. Nature, 546(329). doi:10.1038/546329a.

EIA. (2016). Country Analysis Brief: Mexico. Retrieved from U.S. Energy Information Administration: https://www.eia.gov/beta/international/analysis.php?iso=MEX

EIA. (2019a). Total Energy. Retrieved from U.S. Energy Information Administration: https://www.eia.gov/totalenergy/data/browser/?tbl=T12.06\#/?f=M

EIA. (2019b). Electricity Data Browser. Retrieved from U.S. Energy Information Administration: https://www.eia.gov/electricity/data/browser/

Global CCS Institute. (2019). The Global Status of CCS - 2018. Retrieved from Global CCS Institute: http://status.globalccsinstitute.com/. 
Godec, M.L., Kuuskraa, V., Van Leeuwen, T., Melzerb, L. S., \& Wildgust, N. (2011). $\mathrm{CO}_{2}$ Storage in Depleted Oil Fields: The Worldwide Potential for Carbon Dioxide Enhanced Oil Recovery. Energy Procedia, 4, 2162-2169.

Godec M.L. (2011), Global Technology Roadmap for CCS in Industry. Advanced Resources International. United Nations Industrial Development Organization. Retrieved from https://www.unido.org/sites/default/files/2011-05/EOR_0.pdf

González-Díaz, A., González-Díaz, M.O., Alcaráz-Calderón, A.M., Gibbins J., \& Lucquiaud M. (2017). Priority projects for the implementation of CCS power generation with enhanced oil recovery in Mexico. International Journal of Greenhouse Gas Control, 64, 119-125. Retrieved from https://www.sciencedirect.com/science/article/pii/S1750583616307010\#bib0035

IEA. (2009). $\mathrm{CO}_{2}$ Storage in Depleted Oilfields: Global Application Criteria for Carbon Dioxide Enhanced Oil Recovery, Technical Report, 2009-12. International Energy Agency.

IEA. (2018). IEA EOR Project dataset. Retrieved from International Energy Agency: https://www.iea.org/newsroom/news/2018/november/whatever-happened-to-enhanced-oilrecovery.html

IEA. (2019). Electricity generation by fuel: Mexico 1990 - 2016, IEA Statistics. Retrieved from International Energy Agency: https://www.iea.org/statistics/?country=MEXICO\&year=2016\&category=Electricity\&indicator= ElecGenByFuel\&mode $=$ chart\&dataTable $=$ ELECTRICITYANDHEAT

Kuuskraa V., \& Wallace M. (2014). $\mathrm{CO}_{2}$ EOR set for growth as new $\mathrm{CO}_{2}$ supplies emerge. Oil and Gas Journal, 112(4) 92-105.

Lacy R., Serralde A., \& Climent M.V.M. (2013). Initial assessment of the potential for future CCUS with EOR projects in Mexico using $\mathrm{CO}_{2}$ captured from fossil fuel industrial plants. Int. J. Greenh. Gas Control, 19, 212-219. Retrieved from http://www.sciencedirect.com/science/article/pii/S1750583613002958

Melzer, L.S. (2012). Carbon dioxide enhanced oil recovery $\left(\mathrm{CO}_{2} \mathrm{EOR}\right)$ : factors involved in adding carbon capture, utilization and storage (CCUS) to enhanced oil recovery. Midland, TX: Carbon Capture Coalition. Retrieved from http://carboncapturecoalition.org/wpcontent/uploads/2018/01/Melzer_CO2EOR_CCUS_Feb2012.pdf

Mexican Ministry of Energy. (2014). CCUS technology road map in Mexico. Retrieved from Government of Mexico: https://www.gob.mx/sener/documentos/technology-roadmap-ccus

NEB. (2019). Canada Energy Regulator. Retrieved from National Energy Board, Government of Canada: http://www.neb-one.gc.ca/index-eng.html

NETL. (2010). Carbon dioxide enhanced oil recovery: untapped domestic energy supply and long-term carbon storage solution. Retrieved from National Energy Technology Laboratory, Strategic Center for Natural Gas and Oil (SCNGO): https://www.netl.doe.gov/sites/default/files/netlfile/CO2_EOR_Primer.pdf

NETL. (2015). NATCARB/ATLAS, Carbon Storage Atlas. Retrieved from National Energy Technology Laboratory: https://www.netl.doe.gov/coal/carbon-storage/strategic-program-support/natcarbatlas

NETL. (2019). Enhanced Oil Recovery. Retrieved from National Energy Technology Laboratory: https://netl.doe.gov/oil-gas/oil-recovery

Sacuta N., Daly D., Botnen B., \& Worth K. (2017). Communicating about the geological storage of carbon dioxide - comparing public outreach for $\mathrm{CO}_{2} \mathrm{EOR}$ and saline storage projects. Energy Procedia, 114, 7245-7259

Tollefson, J. (2017). Trump pulls United States out of Paris climate agreement. Nature News, 546(198). Retrieved from: http://www.nature.com/articles/n-12333274

UN. (2019). United Nation Treaty Collection, CHAPTER XXVII, 7.d Paris Agreement. Retrieved from United Nations Framework Convention on Climate Change: https://reaties.un.org/doc/Publication/MTDSG/Volume\%20II/Chapter\%20XXVII/XXVII-7d.en.pdf 
UNFCCC. (2019). INDCs as communicated by Parties. Retrieved from: https://www4.unfccc.int/sites/submissions/indc/Submission\%20Pages/submissions.aspx

The World Bank. (2019). World Development Indicators. Retrieved from The World Bank: http://datatopics.worldbank.org/world-development-indicators/ 